\title{
Possible Role of Copper and Sodium Chloride in Prebiotic Evolution of Peptides
}

\author{
Michael G. SChWEndinger ${ }^{\dagger}$ and Bernd M. Rodet \\ Institute for Inorganic and Analytical Chemistry, University of Innsbruck, \\ Innrain 52a, A-6020 Innsbruck, Austria
}

\begin{abstract}
Peptide synthesis from amino acids has been shown to occur in aqueous solutions at high concentrations of sodium chloride and in the presence of $\mathrm{Cu}(\mathrm{II})$ after several days at $85^{\circ} \mathrm{C}$, under nitrogen or air as well. $\mathrm{Di}$ - and tripeptides could be obtained in a series of experiments which have yet to be optimized. However, these experiments have proved the principle applicability of a model which is based on the structural features of concentrated aqueous $\mathrm{NaCl}$ solutions and evidence of catalytic effects in peptide condensation reactions exerted by di- and trivalent metal ions. Among the ions of $\mathrm{Mg}, \mathrm{Ca}, \mathrm{Cr}, \mathrm{Mn}, \mathrm{Co}, \mathrm{Ni}, \mathrm{Fe}, \mathrm{Cu}, \mathrm{Zn}$ and $\mathrm{Cd}$, only copper was found to be active under these conditions. This leads to new aspects for possible prebiotic peptide syntheses based on a very simple system of only water, amino acids and mineral salts.
\end{abstract}

Keywords Chemical evolution, peptide synthesis, prebiotic peptide formation, peptide formation, metal catalyzed peptide formation

Proteins are one of the classes of compounds which are fundamental to life on earth. The possibility of peptide formation during molecular evolution has been and still is one of the most interesting research topics. Most experimental approaches to evolutionary peptide formation have been based on Oparin's hypothesis of precursor molecules in the atmosphere of primitive earth and amino acid formation under such conditions $\mathbf{1}^{1,2}$ as well as subsequent enrichment. More recently, however, the time at which life appeared on earth had to be pushed back due to the discovery of bacterial microfossiles. It is now assumed that life started at least 4 billion years ago. ${ }^{3,4}$ Assumig that the planet's suface was too hot for water condensation before that time, Woese ${ }^{5}$ has postulated that life first developed in atmospheric aerosols ("salty water droplets", representing a primitive type of "organisms" with a simple form of biochemistry). This theory contradicts most of the hypotheses presented so far regarding peptide formation. Woese's hypothesis has not remained uncriticized: counterarguments have concentrated on the short lifetime of such droplets in a -probably quite unsteady - atmosphere and immediate pyrolysis of contained organic molecules upon contact with the -assumedly still very hot- earth surface. ${ }^{6}$ It seems to be useful, therefore, to summarize very briefly the experiments which have attempted to elucidate the basis

† In partial fulfillment of graduate thesis requirements.

it Author for correspondance. of peptide formation of the earth's surface in a condensed state.

These basic studies can be divided into two groups, according to whether reactions in solution or a melt/ solid state underlie peptide synthesis.

In an aqueous solution, peptides have been shown to form amino acids only in the presence of specific condensation reagents as cyanamides or polyphosphates $^{7-15}$, especially with a considerable excess of such heterocyclic compounds as triazole or imidazole and $\mathrm{Mg}(\mathrm{II})$ ions. $^{7-9}$ The formation of molecules like polyphosphates or imidazole could have taken place under the assumed prebiotic conditions. ${ }^{16,17}$ However, some questions remain open. In the case of polyphosphates, for instance, one energy-rich molecule per peptide bond formed would be needed and, hence, large concentrations or a rapid regeneration mechanism of these molecules. The most likely presence of even a moderate concentration of $\mathrm{Ca}$ (II) or heavier metal ions would have prevented such conditions due to precipitation. Additionally, the destruction of active phosphates by hydrolysis also takes place. This means that they should be formed in sufficient amount and brought to reaction with amino acids within a relatively short time. The experimental conditions for imidazole formation also lead to quite specific requirements regarding the simultaneous availability of compounds on primitive earth. ${ }^{16}$

The second mechanism claimed to have possibly occurred under prebiotic conditions is based on the 
reactions of molten amino acids, assuming that the evaporation of water could have taken place, leading to mixtures of solid amino acids which, in turn could melt due to volcanic heat. In such melts, proteinoids with very interesting properties have been shown to form ${ }^{18}$, leading to microspheres upon reaction with water. Two principle problems have been associated with this hypothesis: the very limited temperature interval between melting and decomposition of amino acids $\left(120-200^{\circ} \mathrm{C}\right)$, and the following question: would a large excess of mineral salts, which should surely be associated with the amino acids after complete evaporation of primordial seawater, not prevent substantial reactions between them. The use of phosphoric acid as a solvent could lower the condensation temperature to $60^{\circ} \mathrm{C}$; however, the formation of such solutions is regarded as very unlikely under primordial conditions. ${ }^{19}$ Though condensation reagents also allow a similar lowering of the reaction temperature ${ }^{19,20}$, their availability is associated with the same problems as mentioned above.

This summary of hypothetical process leading to peptides under primitive earth conditions shows that this part of chemical evolution has not yet been fully explained. A search for more simple ways to explain prebiotic peptide formation still seemed to be worthwhile.

Our approach was therefore based on the consideration of a simpler primordial system containing only water, mineral salts and amino acids, with modest thermal energy available. Some theoretical foundations leading to this model design are discussed in the following section.

\section{The Model}

Thermodynamically, the equilibrium amino acids $\rightleftharpoons$ water+peptide is strongly located on the side of free acids $^{21}$, and the ionic structure of amino acids at virtually every $\mathrm{pH}$ value prevents a nucleophilic substitution of amino $\mathrm{N}$ at carbonyl $\mathrm{C}$, in contrast to amino acid esters. ${ }^{22}$ A second reaction removing water from this equilibrium, should therefore be one condition; for the formation of the peptide bond, a simple catalyst seemed unavoidable. It is, in fact, known that metal ions can catalyze the formation of peptide esters from the corresponding amino acid esters, mostly in ethanol ${ }^{23}$, but in one case - $\mathrm{Co}$ (III) - also in water. ${ }^{24}$ The yields of dipeptides reach 50\%; higher peptides can also be found. However, due to the use of esters and mostly nonaqueous solvents, these studies have not been related to chemical evolution. Molecular orbital calculations regarding the model system gly $+\mathrm{NH}_{3} \rightleftharpoons$ gly$\mathrm{NH}_{2}$ with $\mathrm{Mg}(\mathrm{II})$ as a catalyst have shown, on the other hand, that the metal ion induces a drastic reduction in the activation and reaction energies as well. ${ }^{25-27}$ For our model we therefore assumed that metal ions, existing within the numerous mineral salts dissolved in a prebiotic ocean (or Woese's "salty droplets"), should be the desired catalyst.

Looking at thermodynamical data concerning the simplest amino acid, glycine ${ }^{21}$, the condensation reaction $2 \mathrm{gly} \rightleftharpoons(\mathrm{gly})_{2}+\mathrm{H}_{2} \mathrm{O}$ is characterized by $\Delta H=5.5 \mathrm{kcal} /$ $\mathrm{M}$ and $\Delta S=5.9 \mathrm{cal} / \mathrm{deg} \mathrm{M}$, which leads to $\Delta G=3.4 \mathrm{kcal} /$ $\mathrm{M}$ for $85^{\circ} \mathrm{C}$, a temperature which can be assumed to be reasonable for either solution or droplet conditions. The associated equilibrium constant is $8.41 \mathrm{E}-03$; thus, less than $0.01 \%$ of gly would be converted into (gly $)_{2}$ in an aqueous solution (with over $50 \mathrm{M}$ of water). If the solvent concentration (or its availability, as will be shown soon) decreases, the equilibrium is shifted, and for the case where $c\left(\mathrm{H}_{2} \mathrm{O}\right)--\rightarrow 0$, a limiting value of about $7 \%$ (gly $)_{2}$ in relation to $c$ (gly) is reached, quite sufficient for synthetic purposes, from a thermodynamic viewpoint.

Our ideas concerning the water-removing process are based on the data available from quantum chemical and Monte Carlo simulation studies on sodium chloride solutions. ${ }^{28-30}$ These investigations have supplied quite reliable data concerning the ion-water interaction energies and the average coordination numbers of the ions, in good agreement with experimental diffraction data, as far as they are available. They have supplied further structural data which is not easily accessible from experiments, such as the concentration dependence of the coordination number distributions and water molecule orientations. ${ }^{28}$ An evaluation of these data has led to the conclusion that above a concentration of $0.5 \mathrm{M} \mathrm{NaCl}$, the solution structure changes, and is ever more characterized by the dominance of solvation water over bulk. At higher $\mathrm{NaCl}$ concentrations (3$4 \mathrm{M}$ ) almost all water present is first shell solvation water of the ions, partly shared by them, and bound to the ions by energies between $12-18 \mathrm{kcal} / \mathrm{M}$. This value is much higher than the $\Delta H$ value for (gly) ${ }_{2}$ formation. At these concentrations, $\mathrm{Na}$ and $\mathrm{Cl}$ ions can be characterized as being "unsaturated" in solvation; they will thus be able to bind additional water molecules that become available through any reaction. We therefore assumed that this process could have created the thermodynamic conditions for substantial peptide synthesis in aqueous solution, starting from amino acids. Sodium chloride was present in abundance, and the necessary concentrations could easily be achieved locally by the evaporation of water.

It could not be assumed, however, that sodium ions are also a sufficient catalyst for lowering the activation energies, because of their poor binding ability to amino acids and their limited polarizing power. Thus, in our model we expect di- or trivalent ions to play the role of a catalyst: ions, the availability of which seems reasonable and which might have played a role in peptide and protein chemistry up to now. Either of these ions would also be strongly solvated in water (thus cooperating in the aforementioned effect); but their binding to amino acids should be favored over binding to water. This view led to a first (and still quite incomplete) selection of ions: $\mathrm{Mg}, \mathrm{Ca}, \mathrm{Cr}, \mathrm{Mn}, \mathrm{Co}, \mathrm{Ni}$, 
$\mathrm{Cu}, \mathrm{Zn}$ and $\mathrm{Cd}$. These were then investigated in our experiments. Besides catalysis, some of these ions could further enhance peptide synthesis by the binding of products in complex form, making them available for the addition of further amino acids, and, thus producing higher peptides.

\section{Experimental Evaluation of the Model}

For a first orientation, a series of experiments has been designed, in which aqueous solutions of the following composition were prepared: $0.8 \mathrm{M}$ glycine, $5 \mathrm{M}$ sodium chloride, and $0.4 \mathrm{M}$ of the metal salts of the aforementioned selection. The analytical-grade reagents were mixed and all solutions were freed of traces of oxygen by passing nitrogen through them. They were then kept at $85^{\circ} \mathrm{C}$ under nitrogen atmosphere (exclusion of external factors) and with a reflux column, so that concentrations remained rather constant throughout the process. The pH of the solutions was not influenced by any additional measures and, hence, varied according to the metal ion used, from 2.3-5.1. After 7 days, $0.25 \mathrm{ml}$ samples were taken, and after adjusting the $\mathrm{pH}$ to 2 by a citrate/ $\mathrm{HCl}$ buffer, salts were removed by the ion exchange on acidic Fluka KA Amberlite IR-120 in its ammonium form and subsequent elution with $0.5 \mathrm{M} \mathrm{NH}_{3}$. The purified solution containing organic substances was analyzed by thinlayer chromatography with ninhydrine staining.

Among all ions investigated only $\mathrm{Cu}$ (II) led to a new compound, clearly separated and well visible in the chromatograms. By simultaneous chromatography with reference compounds, the $R_{\mathrm{f}}$ value was found to be identical with that of reagent-grade glycylglycine, so that the formation of a peptide bond had to be assumed.

The whole series was then repeated with 2 samples for each of the ions which previously showed negative results, confirming that no detectable amounts of new compounds form, even at increased metal concentrations.

For copper ion, 20 more samples were prepared with varying concentrations $(\mathrm{Cu}$ : $0.2-0.4$, gly: $0.4-0.8$, $\mathrm{NaCl}: 0.0-5.0 \mathrm{M}$ ) and other constant conditions. (gly) formation was observed for all gly and $\mathrm{Cu}(\mathrm{II})$ concentrations within that range, steadily increasing with the concentration. Decreasing the $\mathrm{NaCl}$ concentration resulted in continuously smaller amounts of dipeptide; at $0.5 \mathrm{M} \mathrm{NaCl}$ no more dipeptide could be found. Using larger sample amounts from solutions with high concentration $(0.8 \mathrm{M}$ glycine, $0.4 \mathrm{M}$ copper and $>4 \mathrm{M}$ $\mathrm{NaCl}$, one more spot appeared on the chromatograms, identified as (gly) ${ }_{3}$ and, thus, also indicating that higher peptides can form under these conditions. An evaluation of the thin-layer chromatograms gave a dipeptide concentration of at least $1 \%$ of the remaining glycine, considerably less than the amount of tripeptide. Within this new series, copper ions have been removed by precipitation with hydrogen sulfide prior to the removal
Table I Summary of experimental results for $\mathrm{Cu}(\mathrm{II}) / \mathrm{gly} /$ $\mathrm{NaCl}$ system

\begin{tabular}{ccccc}
\hline$c($ gly $) /$ & $c(\mathrm{NaCl}) /$ & $c(\mathrm{Cu}(\mathrm{II})) /$ & $(\mathrm{gly})_{2}$ & $(\mathrm{gly})_{3}$ \\
$\mathbf{M}$ & $\mathrm{M}$ & $\mathrm{M}$ & - & - \\
0.4 & 0.0 & 0.2 & - & - \\
0.4 & 0.5 & 0.2 & - & - \\
0.4 & 3.0 & 0.2 & + & - \\
0.4 & 5.0 & 0.2 & + & - \\
0.4 & 5.0 & 0.0 & - & - \\
0.8 & 0.0 & 0.4 & - & - \\
0.8 & 0.5 & 0.4 & - & - \\
0.8 & 3.0 & 0.4 & + & + \\
0.8 & 5.0 & 0.4 & ++ & + \\
0.8 & 5.0 & 0.0 & - & - \\
\hline
\end{tabular}

- , not detected; + , clearly detected; ++ , larger amounts; $(+)$, traces.

of $\mathrm{NaCl}$ by ion exchange, in order to assure that no reaction could have taken place through $\mathrm{Cu}$ (II) bound to the exchange resin. A few more experiments have been performed with free access to air. The identical results obtained thereby showed that the process could have taken place even under an oxidizing atmosphere.

A control experiment with glycine and $\mathrm{NaCl}$ alone, leading to no detectable dipeptide concentration, confirmed that both $\mathrm{NaCl}$ and $\mathrm{Cu}(\mathrm{II})$ were essential for the reaction.

The dipeptide fraction was finally isolated by means of the column separation on silica gel 60 (Merck), and unambiguously identified by its IR spectrum after preparing the 2,4-dinitro-fluorophenyl derivative, as glycylglycine. The results of all experiments are summarized in Table 1. In order to obtain some new information about the general applicability of the synthesis, glycine was substituted by DL-alanine under otherwise identical conditions. Alanylalanine could be detected; the peptide concentration obtained in this experiment appeared to be similar to that obtained with glycine.

\section{Conclusions}

1. The results presented here strongly indicate that peptide formation could have occurred under very simple conditions, which are more likely to have been realized on primitive earth. Sodium chloride and copper ions can be assumed to have been ubiquitously present, as indicated by precambrian "green zones" containing malachite and azurite (basic carbonates), and in accordance with the assumption that precambrian oceans acted as accumulators of divalent ions. ${ }^{31}$ The peptide synthesis conditions allowed a considerable variation in the concentration of these two essential substances.

2. The model proposed here and its experimental conditions avoid virtually all uncertainties concerning the existence, stability and availability of hypothetical 
condensation reagents under the conditions of primitive earth. ${ }^{32}$ No energy-rich molecules or organic catalysts are needed. The necessary $\mathrm{NaCl}$ concentrations could have been easily estalished by evaporation and most of the copper ions, acting as catalyst, could return into solution after having induced a synthesis. Thus, no continuous supply of larger amounts of this metal seems to have been necessary. Some of the ions, however, could have formed complexes with low peptides and, hence, the basic structures for synthesis of higher peptides. The processes seem to be independent of the composition of the primordial atmosphere, and no heterogenous reaction with surface materials (e.g. lay, kaoline) is needed.

3. This mechanism could have occurred, in principle, either in solution on the earth's surface or in the hypothetical "salty droplets" of an aerosol, provided that their average lifetime was sufficiently long.

4. The essential role of $\mathrm{Cu}$ (II) emerging from this work seems to be consistent with several other biological facts. Copper is still the most abundant transition metal ion found in seawater. ${ }^{33}$ It has played a prominent role in protein and enzyme chemistry until today (e.g. hemocyanine, ceruloplasmine, and some 12 essential enzymes), and seems to be involved in protein growth in connection with the peptide hormone $\mathrm{GLH}^{34,35}$, forming mixed complexes with the hormone as one ligand. ${ }^{36}$ Finally, the catalytic activity of copper in peptide synthesis starting from amino acid esters in nonaqueous solvents is also superior to that of other metal ion ${ }^{23}$, indicating a very specific suitability of this ion for natural peptide synthesis as well.

5. We therefore assume that copper and sodium chloride could have played a very essential role in chemical evolution, and that further investigations in this direction, especially concerning the optimization of the conditions and details of the reaction mechanism, would be most valuable. The experimental evidence, that the physico-chemical properties of electrolyte solutions are subject to characteristic changes at certain concentrations ${ }^{37}$, also seems to be of specific interest with respect to the role of salts in the possible prebiotic way to peptides indicated by our results. It can be hoped, that with more sophisticated analytical methods and equipment, hitherto undetected higher oligomers and other valuable information will be found.

\section{References}

1. G. Schlesinger and S. L. Miller, J. Mol. Evol., 19, 376 (1983).

2. K. Harada and S. W. Fox, Nature [London], 201, 335 (1964).

3. H. D. Pflug, W. Meinel, K. H. Neumann and M. Meinel, Naturwiss., 56, 10 (1969).

4. H. D. Pflug, Naturwiss., 71, 63 (1984).
5. C. R. Woese, J. Mol. Evol., 13, 95 (1979).

6. S. Scherer, J. Mol. Evol., 22, 91 (1985).

7. J. Hulshof and C. Ponnamperuma, Orig. Life, 7, 197 (1976).

8. J. Rabinowitz and A. Hampai, J. Mol. Evol., 21, 199 (1985).

9. J. Yamanaka, K. Inomata and Y. Yamagata, Orig. Life, 18, 165 (1988).

10. J. R. Hawker and J. Oro, J. Mol. Evol, 17, 285 (1981).

11. M. Paecht-Horowitz, J. Berger and A. Katchalsky, Nature [London], 228, 636 (1970).

12. D. W. Mullins, Jr. and J. C. Lacey, J. Mol. Evol., 15, 339 (1980).

13. J. Rishpon, P. O'Hara, N. Lahav and J. Lawless, J. Mol. Evol., 18, 179 (1982).

14. A. L. Weber, J. M. Caroon, J. T. Warden, and R. M. Lemmon and M. Calvin, BioSystems, 8, 277 (1977).

15. J. J. Flores and J. O. Leckie, Nature [London], 244, 435 (1973).

16. J. Oro,S. Basile, S. Cortes, C. Shen and T. Yamron, Orig. Life, 14, 237 (1984).

17. R. Osterberg and L. E. Orgel, J. Mol. Evol., 1, 241 (1972).

18. S. W. Fox and K. Dose, "Molecular Evolution and the Origin of Life", Rev. Ed., Marcel Deccer Inc., New York, 1977.

19. H. Sawai, R. Lohmann and L. E. Orgel, J. Mol. Evol, 6, 165 (1975).

20. H. Sawai and L. E. Orgel, J. Mol. Evol., 6, 185 (1975).

21. A. B. Meggy, J. Chem. Soc., 1956, 1444.

22. R. W. Hay and L. J. Porter, J. Chem. Soc., 1967, 1261.

23. S. Yamada, S. Wagatsuma, Y. Takeuchi and B. Terashima, Chem. Pharm. Bull., 19, 2380 (1971).

24. D. A. Buckingham, D. M. Foster and A. M. Sargeson, J. Am. Chem. Soc., 92, 5701 (1969).

25. T. Oie, G. H. Loew, S. K. Burt, J. S. Binkley and R. D. MacElrov, J. Am. Chem. Soc., 104, 6169 (1982).

26. T. Oie, G. H. Loew, S. K. Burt and R. D. MacElroy, J. Am. Chem. Soc., 105, 2221 (1983).

27. T. Oie, G. H. Loew, S. K. Burt and R. D. MacElory, J. Am. Chem. Soc., 106, 8007 (1984).

28. J. P. Limtrakul, S. Fujiwara and B. M. Rode, Anal. Sci., 1, 29 (1985).

29. J. P. Limtrakul, M. M. Probst and B. M. Rode, J. Mol. Structure, 121, 23 (1985).

30. J. P. Limtrakul and B. M. Rode, Mh. Chemie, 116, 1377 (1985).

31. P. E. Cloud, Econ. Geol., 68, 1135 (1973).

32. C. Ponnamperuma, "Origin of Life", pp. 67-81, Japan Scientific Soc. Press, Tokyo, 1978.

33. R. W. Hay, "Bioinorganic Chemistry", E. Horwood Series of Chem. Science, Chichester/GB, 1984.

34. L. Pickart and M. M. Thaler, Nature New Biol., 243, 85 (1973).

35. L. Pickart and M. M. Thaler, J. Cell Physiol., 102, 129 (1980).

36. M. J. A. Rainer and B. M. Rode, Inorg. Chim. Acta, 92, I (1984).

37. S. Fujiwara, Anal. Sci., 4, 123 (1988).

(Received October 26, 1988). (Accepted November 14, 1988). 